(1)

GeOrge Fox

UNIVERSITY

\section{Digital Commons @ George Fox University}

Faculty Publications - Doctor of Psychology (PsyD) Program

2017

The Effects of Grace Interventions in Church Communities

Rodger K. Bufford

Mark R. McMinn

Jeff A. Moody

Laura Geczy-Haskins

Follow this and additional works at: https://digitalcommons.georgefox.edu/gscp_fac

Part of the Christianity Commons, and the Psychology Commons 


\title{
The effects of grace interventions in church communities*
}

\author{
Rodger K. Bufford, Mark R. McMinn, Jeff A. Moody and Laura Geczy-Haskins $^{\S}$ \\ Graduate Department of Clinical Psychology, George Fox University, Newberg, Oregon, USA
}

\begin{abstract}
Grace remains little studied though several recent studies have developed promising ways to measure grace. Here we report two studies involving grace interventions as part of an ongoing investigation of positive psychology in the context of Christian church communities, Study One used a crossover design in which two congregations were measured on grace and other variables at the outset, and again after phases one and two. One congregation received a grace intervention during phase one and the second during phase two. Results showed increased scores on grace but not an expected increase in marital satisfaction among married participants. Study Two used a similar design with two additional congregations to assess effects of a grace intervention on selfforgiveness. As expected, congregants receiving the grace intervention showed increases in trait self-forgiveness when compared to those in the wait-list.
\end{abstract}

\section{ARTICLE HISTORY}

Received 12 August 2016

Accepted 13 June 2017

\section{KEYWORDS}

Positive psychology; grace; Christianity; self-forgiveness
Although positive psychology has been a focus of ongoing research for almost two decades (Seligman \& Csikszentmihalyi, 2000; Seligman, Steen, Park, \& Peterson, 2005), grace has received little empirical attention despite being a good fit within the domain. Grace involves a free gift (McMinn, 2008) or getting better than we deserve (Bufford, Sisemore, \& Blackburn, 2014). Thus giving a gift, forgiving an injury or debt, and pardoning an offense or slight are all considered acts of grace. The contemporary idea that we can 'pay it forward' may be an example of grace provided we do not expect something in return. A few studies have shown a correlation between grace and wellbeing (Sisemore et al., 2011; Watson, Chen, \& Sisemore, 2011; Watson, Morris, \& Hood, 1988a,b) although the grace measures used were relatively brief and lacked psychometric support. Recently a handful of studies developed validated ways to measure grace (Bassett and the Roberts Wesleyan College Psychology Research Group, 2013; Bufford, Blackburn, Sisemore, \& Bassett, 2015; Bufford, Sisemore, \& Blackburn, 2017; Patrick, Beckenbach, Sells, \& Reardon, 2013; Sisemore et al., 2011).

In contrast to the relatively sparse literature on grace, over 1000 articles have been published on interpersonal forgiveness. A relatively small portion of these have focused on self-forgiveness (e.g. Hall \& Fincham, 2005;
Woodyatt \& Wenzel, 2013). The question of how selfforgiveness and acceptance of responsibility are related led to emergence of the concept of pseudo self-forgiveness (Wenzel, Woodyatt, \& Hedrick, 2012; Wohl, DeShea, \& Wahkinney, 2008), where one appears to be self-forgiving but in actuality is simply refusing to take responsibility for the harm that has been done. In contrast, genuine self-forgiveness involves accepting full responsibility for harming oneself or others while also choosing to release oneself from self-recrimination. Research on the relationship between self-forgiveness, religion, and spirituality is limited and lacks consensus (Exline, Yali, \& Lobel, 1999; Hall \& Fincham, 2005; Leach \& Lark, 2004; McConnell \& Dixon, 2012; Toussaint \& Williams, 2008; Walker \& Gorsuch, 2002).

As part of an effort to promote the implementation of positive psychology in church settings we conducted two interventional studies that explored whether it is possible to increase the experience of grace and self-forgiveness among members of local church congregations.

\section{Study One}

We were interested in assessing the effects of a grace intervention in two Christian congregations, both with regard to parishioners' experience of grace and other variables

CONTACT Rodger K. Bufford rbufford@georgefox.edu

*Results of Study One were initially reported in a dissertation by Jeff Moody; data were re-analyzed for this report. Results of Study Two were initially reported in a dissertation by Laura Geczy-Haskins.

${ }^{\ddagger}$ Jeff A. Moody is now at Philhaven Hospital, Mt. Gretna, PA.

sLaura Geczy-Haskins is now at the VA Medical Center, Syracuse, NY.

(4) Supplemental data for this article can be accessed at https://doi.org/10.1080/17439760.2017.1350740.

๑) 2017 Informa UK Limited, trading as Taylor \& Francis Group 
related to psychological and spiritual wellness. Because grace is a relational construct, typically experienced as a gift from one person to another, and because marriage typically involves frequent interactions between the same two people sustained over time, we expected that a congregational grace campaign might have particularly beneficial implications for married parishioners.

\section{Methods}

\section{Participants}

Participants included volunteers from two Friends (Quaker) churches in the Pacific Northwest. Both were moderately sized churches with several hundred members or regular attendees. We sought to recruit a subset of approximately 30 people per congregation to complete an extensive battery of questionnaires at three time periods. The initial sample included 55 participants with 31 in Congregation A and 24 in Congregation B. All participants were assessed at Time One. Congregation $A$ then received the grace intervention. Both groups were tested a second time (Time Two). Congregation $B$ then received the grace intervention. Finally, both groups were assessed again at Time Three after the intervention for Congregation B. A total of 47 participants completed Time Two and Time Three testing and were included in the results. Among these, 17 were male (36\%) and 28 female (60\%), with two (4\%) unidentified; 37 (79\%) identified as European American, 8 (17\%) as 'other', 1 as Hispanic/Latino (2\%) and one (2\%) did not respond. Average age was 54.7 years (standard deviation $=14.4$ ) and 37 (77.1\%) were married. For highest level of education, 5 (8.5\%) reported high school diplomas, 11 (23.4\%) reported some college courses without a degree, $19(40.4 \%)$ reported college degrees, one (2.1\%) currently attending graduate school, and 12 (25.5\%) reported graduate degrees. Thirtyone $(66 \%)$ reported current employment, with the rest (16; $34 \%)$ reporting no current employment.

\section{Instruments}

Dimensions of Grace Scale (DGS). The DGS is a 36-item measure developed by Bufford et al. (2017). Each item is responded to on a 7-point continuum from $1=$ Strongly Disagree to 7 = Strongly Agree. It consists of five subscales: God's Grace, Costly Grace, Grace to Self, Grace from Others, and Grace to Others. Each sub-scale has seven items except the God's Grace subscale, which has eight. Bufford et al. (2017) provided evidence of good internal consistency (alphas ranged from .71 to .98), convergent and discriminant validity, and showed that each of the five subscales contributed unique predictive variance. The DGS was the primary outcome measure to assess the grace intervention. Internal consistency (coefficient alpha) for DGS at Time One was .82. Alpha was .63, .84, $.58, .75$, and .81 for the God's Grace, Costly Grace, Grace to Self, Grace to Others, and Grace from Others subscales respectively. The test-retest correlation for DGS using Time One and Time Two scores for the control group was .90 after six weeks.

Daily Spiritual Experiences Scale (DSES). The DSES is a 16-item self-report measure to identify everyday experiences of the transcendent rather than assess beliefs or behaviors (Underwood, 2011; Underwood \& Teresi, 2002). Reports of transcendent experiences are collected on a frequency continuum from 0 (never or almost never) to 5 (many times a day); we re-coded it to a 1-6 continuum to avoid zeroes. Concurrent validity has been shown with a number of R/S and other measures. Test-retest reliability is reported as .85 and internal consistency at .89-.95. Alpha for the DSES was .93 at Time One.

Duke Religion Index (DUREL). The DUREL is a fiveitem measure of religiousness (Koenig \& Bussing, 2010). One item measures organizational and a second nonorganizational religiousness; each of these items is responded to on a continuum from 1 (never) to 6 (more than once per week). The remaining three items measure intrinsic orientation and are responded to on a continuum from 1 (defintely not true of me) to 5 (definitely true of me). Koenig, Meador, and Parkerson (1997) reported an alpha of .75 and Storch, Strawser et al. (2004) reported testretest reliability of .91. Koenig and Busing (2010) reported strong convergent validity. Alpha for the thee intrinsic orientation items was 69 at Time One.

Enrich Marital Satisfaction Scale (EMS). The EMS is a fifteen item scale with subscales of ten items measuring Marital Satisfaction and five measuring Idealistic Distortion (Fowers \& Olson, 1993). Items use a 5-point continuum from 1 (strongly disagree) to 5 (strongly agree). Although brief, Fowers and Olson report that it has good concurrent validity with longer marital satisfaction scales. Internal consistency and test-retest reliability are both reported as .86 . Alpha was .85 in the present sample for Time One.

Gratitude Questionnaire-6 (GQ-6). The GQ-6 is a 6-item scale (McCullough, Emmons, \& Tsang, 2002) designed to measure gratitude. Items are responded to on a 7-point continuum from 1 (strongly disagree) to 7 (strongly agree). The GQ-6 shows small negative correlations with anxiety and depression, indicating gratitude is relatively independent of them rather than an opposite. In predicting psychological wellbeing, the GQ-6 provided incremental validity above the Big Five personality traits (Wood, Joseph, \& Maltby, 2009). Internal consistency of .87 was reported in their study. Alpha for GQ-6 at Time One was .73. 
Table 1. Research design for Study One and Study Two.

\begin{tabular}{lclccc}
\hline Participants & Assessment 1 & Treatment 1 & Assessment 2 & Treatment 2 & Assessment 3 \\
\hline Congregation A & $\mathrm{X}$ & Grace Emphasis & $\mathrm{X}$ & Post-treatment & $\mathrm{X}$ \\
Congregation B & $\mathrm{X}$ & Wait List & $\mathrm{X}$ & Grace Emphasis & $\mathrm{X}$ \\
\hline
\end{tabular}

Notes: At Assessment 1 data were gathered with various self-report measures and a demographic questionnaire; all measures but the demographic questionnaire were repeated at Assessments 2 and 3 .

Positive and Negative Affect Schedule (PANAS). The PANAS includes two subscales of ten items each that assess positive and negative affect respectively (Watson, Clark, \& Tellegen, 1988). Respondents are given a time frame ranging from the present moment to their lifetimes. Each item is an adjective (e.g. interested, guilty) used to rate their experience during this time-frame on an intensity continuum from 1 (very slightly or not at all) to 5 (extremely). Items for the positive affect subscale (PANAS+) and negative affects subscale (PANAS-) are randomly ordered. In a review, Crawford and Henry (2004) concluded that positive and negative affects, as measured by the PANAS, are independent; correlations ranged from -.12 to -.23 . Internal consistency alpha coefficients range from .84 and .90 for the positive and negative affect scales. Strong convergent validity results are reported. In the present sample, alpha at Time One was .88 for PANAS + and .82 for PANAS-.

Positive Psychology Attitude Scale (PPAS). The PPAS was a scale designed for this set of studies to assess the degree to which participants held favorable attitudes toward psychological science. It consisted of six items, such as Positive psychology is a worthwhile endeavor. Participants responded on a 7-point continuum from 1 (Strongly disagree) to 7 (Strongly agree). Alpha in the present study was $.91, .86$ and .92 for Times One, Two, and Three respectively.

Spiritual Well-Being Scale (SWB). The SWB is a twentyitem measure of religious/spiritual wellbeing developed by Ellison and Paloutzian (Ellison, 1983; Paloutzian \& Ellison, 1982). Subscales of Religious Well-Being (RWB) and Existential Well-Being (EWB) consist of ten items each and measure well-being in relationship to God and to self and the world respectively. Items are responded to on a continuum ranging from 1 (strongly disagree) to 6 (strongly agree) with no mid-point. Bufford, Paloutzian, and Ellison (1991) reported alphas above .84 in seven samples and test-retest reliability greater than .85 in three samples. Alpha was .93 for Time One in this sample.

Demographic questionnaire. The demographic questionnaire gathered data on age, education, gender, ethnicity, and employment status.
A thirteen item version of the Marlowe-Crowne Social Desirability Scale was also administered (Crowne \& Marlowe, 1960; Reynolds, 1982).

\section{Procedure}

One of the goals of this study was to approach it in the spirit of church/clergy collaboration proposed by McMinn, Aikins, and Lish (2003). The pastors of the participating churches were invited to collaborate with the researchers in developing the procedures for the grace intervention used in this study. One aim was to develop an intervention that might be more readily adopted by other church congregations, particularly those with similar religious beliefs and organizational practices. Thus experimental control over the procedure was sacrificed in the interest of ecological validity.

As a result of conversations with pastoral leaders of the two congregations a'grace emphasis' campaign was developed with three parts: (1) a sermon series with the focus on grace; (2) a small-group study program, also focused on grace; (3) a menu of personal grace practices that individual members of the congregations could carry out.

The sermon series was comprised of six consecutive weekly Sunday sermons on the biblical concept of grace. Small groups used The Good and Beautiful God by James Bryan Smith (2009) as their primary focus. This text was chosen for its focus on grace and congruence with Friends traditions. Personal grace practices included exercises taken from Smith's book and other sources. Many of the grace practices could be carried out individually, while others involved relational activities with other persons. Married participants were encouraged to practice grace activities with their partners. All activities focused in some way on grace or engaging in public or secret acts of grace toward others. Members of the congregation were free to participate in any or all of these activities.

Members and regular attenders at each participating church who were at least 18 years old were invited to sign up for the initial questionnaire during a Sunday morning service. Members who agreed to participate then completed the study measures via an online surveying website. Because repeated measures were collected, participants were assigned an identification number, which was sent to them by email. They entered the same identification number in subsequent assessments. Identification 
Table 2. Study One means and standard deviations by occasions for all measures.

\begin{tabular}{|c|c|c|c|c|}
\hline Scale & Group & Time $1 \mathrm{M} / \mathrm{SD}$ & Time $2 \mathrm{M} / \mathrm{SD}$ & Time $3 \mathrm{M} / \mathrm{SD}$ \\
\hline \multirow[t]{3}{*}{ DGS } & $A$ & $187.92 / 15.62$ & $196.54 / 16.71$ & $194.57 / 15.84$ \\
\hline & B & $175.68 / 23.46$ & $179.95 / 21.38$ & $184.49 / 20.28$ \\
\hline & Total & $182.31 / 20.34$ & $188.94 / 20.55$ & $189.85 / 18.56$ \\
\hline \multirow[t]{3}{*}{ DSES } & A & $70.98 / 12.32$ & $73.54 / 11.94$ & $73.00 / 10.45$ \\
\hline & B & $66.64 / 11.73$ & $67.89 / 11.12$ & $70.47 / 10.85$ \\
\hline & Total & $68.99 / 12.12$ & $70.95 / 11.80$ & $71.84 / 10.60$ \\
\hline \multirow[t]{3}{*}{ DUREL-1 } & A & $5.50 / .51$ & $5.46 / .51$ & $5.58 / .50$ \\
\hline & B & $5.05 / .58$ & $4.90 / .83$ & $5.00 / .69$ \\
\hline & Total & $5.29 / .58$ & $5.21 / .72$ & $5.31 / .66$ \\
\hline \multirow[t]{3}{*}{ DUREL-2 } & A & $5.77 / .59$ & $5.84 / .48$ & $5.64 / .78$ \\
\hline & B & $5.68 / .65$ & $5.80 / .52$ & $5.50 / .86$ \\
\hline & Total & $5.73 / .61$ & $5.82 / .49$ & $5.57 / .80$ \\
\hline \multirow[t]{3}{*}{ DUREL-I } & A & $25.15 / 1.78$ & $25.80 / 1.36$ & $25.33 / 2.01$ \\
\hline & B & $24.23 / 2.11$ & $23.81 / 2.30$ & $24.27 / 2.31$ \\
\hline & Total & $24.73 / 1.98$ & $24.89 / 2.09$ & $24.84 / 2.20$ \\
\hline \multirow[t]{3}{*}{ EMS } & A & $55.65 / 10.49$ & $57.51 / 7.61$ & $55.95 / 11.10$ \\
\hline & B & $57.51 / 7.62$ & $55.15 / 11.3$ & $56.55 / 7.48$ \\
\hline & Total & $56.50 / 9.20$ & $56.66 / 10.27$ & $56.22 / 9.49$ \\
\hline \multirow[t]{3}{*}{ GQ-6 } & A & $38.35 / 3.57$ & $38.44 / 3.71$ & $38.87 / 2.91$ \\
\hline & B & $37.68 / 4.31$ & $37.23 / 3.96$ & $38.23 / 3.98$ \\
\hline & Total & $38.04 / 3.90$ & $37.88 / 3.84$ & $38.57 / 3.42$ \\
\hline \multirow[t]{3}{*}{ PANAS+ } & A & $35.10 / 6.17$ & $35.81 / 5.73$ & $37.17 / 5.79$ \\
\hline & B & $34.35 / 7.31$ & $35.76 / 5.62$ & $37.13 / 6.38$ \\
\hline & Total & $34.76 / 6.65$ & $35.79 / 5.62$ & $37.14 / 6.00$ \\
\hline \multirow[t]{3}{*}{ PANAS- } & A & $15.92 / 5.11$ & $16.75 / 6.49$ & $14.85 / 3.91$ \\
\hline & B & $18.11 / 4.89$ & $18.09 / 5.08$ & $17.05 / 4.60$ \\
\hline & Total & $16.93 / 5.08$ & $17.37 / 5.86$ & $15.86 / 4.34$ \\
\hline \multirow[t]{3}{*}{ Pos Psych } & A & $33.41 / 7.53$ & $32.12 / 6.19$ & $33.32 / 5.92$ \\
\hline & B & $31.00 / 6.91$ & $31.00 / 6.34$ & $30.00 / 6.50$ \\
\hline & Total & $32.31 / 7.28$ & $31.60 / 6.22$ & $31.80 / 6.35$ \\
\hline \multirow[t]{3}{*}{ SWB-1 } & A & $104.67 / 14.35$ & $105.59 / 12.12$ & $107.00 / 11.82$ \\
\hline & B & $97.37 / 15.51$ & $99.45 / 13.32$ & $101.70 / 11.51$ \\
\hline & Total & $101.33 / 15.18$ & $102.78 / 12.92$ & $104.57 / 11.86$ \\
\hline
\end{tabular}

Notes: $N=47 . \mathrm{DGS}=$ Dimensions of Grace; DSES = Daily Spiritual Experiences; DUREL = Duke Religion Index ( 1 = question 1; 2 = question $2 ; \mid$ = Intrinsic Religiousness); GQ-6 = Gratitude Questionnaire-6; Positive Psych = Positive Attitude Toward Psychology; SWB = Spiritual Well-Being Scale; SWLS = Satisfaction with Life Scale. Scale scores were computed by summing items and replacing missing data with the mean score for the missing item.

numbers were removed prior to data analysis; final data did not retain any personal identifying information. The initial assessment was completed in early February 2015. Congregation A then participated in the grace emphasis while Congregation B served as a wait-list control group. Once Congregation A had completed the grace emphasis phase, data were again gathered near the end of March 2015. Congregation $B$ then began its grace emphasis campaign and final data were gathered for both congregations at the end of this process in late May of 2015. See Table 1 for research design.

Participants who completed all three rounds of questionnaires were given a $\$ 50$ gift card. The Human Subjects Research Committee at George Fox University approved this study.

\section{Results}

Seven participants did not complete all three assessments and were omitted from results. In addition, responses on an occasional item were missing for several other participants.
We used the mean score of that item to replace missing data for each of these occurrences (Pigott, 2001). Fewer that two percent of the items were replaced in this way for any given item-scale-occasion, and less than $0.5 \%$ of the items were replaced for any given occasion. Thus, we were able to salvage the remaining participants with little risk of distorting the results (Enders, 2010; Pigott, 2001). Moody (2016) reported the distribution of items replaced by occasion.

Analyses of variance were performed to assess for any significant differences between Congregation $A$ and Congregation $B$ at the outset. We found no significant differences in age, gender, ethnicity, education, or employment. However, Congregation A scored higher on DUREL attendance, DUREL-I (Intrinsic Orientation), and SWB. Thus Congregation $A$ reported attending services more frequently, a more intrinsic orientation, and higher spiritual wellbeing at Time One. In further analyses we used analysis of covariance to statistically control for initial differences on these significant variables. The groups also differed on DGS at Time One, $F_{(1,46)}=5.56, p=.038$, but did not differ on DGS when we controlled for DUREL attendance, DUREL-I and SWB; $F_{(1,43)}=3.18, p=.082$. On the DGS subscales, the two congregations differed on Costly Grace, but not on God's Grace, Grace to Self, Grace from Others, or Grace to others at Time One; see supplementary Table A. We controlled for Time One scores as well as DUREL attendance, DUREL-I, and SWB on all DGS subscales in assessing treatment effects for the DGS subscales as well. Correlational results showed that the Marlowe-Crowne was significantly related to God's Grace, Grace to Self, and DSES at Time One; thus we also controlled for MCS scores in our analyses of these three measures.

Repeated measures analyses of variance comparing scores on the dependent measures at Time One and Time Two revealed that Congregation A scored significantly higher on the DGS and the DUREL-I, $F_{(1,25)}=7.40 ; p=.012$; and $F_{(1,25)}=8.23 ; p=.008$, respectively at Time Two, but not on the DSES, EMS, GQ-6, PANAS + or PANAS-, POSPsych or the SWB following the initial grace intervention. In contrast, Congregation B showed no changes from Time One to Time Two. When all three times were considered, both congregations showed significant increases on DGS with $F_{(2,50)}=1769.43 ; p<.001$ and $F_{(2,50)}=850.52$; $p<.001$ for Congregation A and Congregation $B$ respectively. Congregation $A$ also showed significant gains on the DUREL-I; $F_{(2,50)}=3.93 ; p=.026$. Neither congregation showed changes on the other dependent measures in these analyses (see Table 2).

In comparisons between congregations we used analysis of covariance to control for pretest differences in the DUREL attendance, DUREL Intrinsic, and SWB scores. Pretest scores for each variable were also controlled. MCS 
scores were also controlled for God's Grace, Grace to Self, and DSES. Results showed a significant difference between congregations for the DGS at Time Two; $F_{(1,42)}=6.92$, $p=.012, \eta^{2}=.14$, but not at Time $3 ; F_{(1,42)}=0.11$, NS. When DGS subscales were examined, Congregation A scored higher than Congregation B on God's Grace at Time Two, $F_{(1,41)}=8.45 ; p=.006, \eta^{2}=.18$, but not at Time 3. No differences were found for Costly Grace, Grace to Self, Grace from Others, or Grace to Others at Time 2. At Time 3 no significance differences were found between Congregation $A$ and Congregation B in similar analyses of covariance.

For the DUREL Intrinsic subscale differences were also found at Time Two, $F_{(1,43)}=9.80, p=.003$, Partial $\mathrm{Eta}^{2}=.19$, but not at Time Three, $F_{(1,43)}=.44$, NS. No other differences were found between congregations at Time Two or Time Three.

We compared married and not married participants to test the hypothesis that marriage may be a crucible for growing in grace. Analyses of variance showed no differences between married and not married participants on the DGS scale at Times 1, 2, or 3. Similar analyses found no differences between married and not married participants for God's Grace, Costly Grace, Grace to Self, and Grace from Others, but a significant difference in Grace to others at Time 1. Using analyses of covariance as before to control for scores at Time 1, we found a significant difference on Grace to Others at Times 2 and 3; $F_{(1,42)}=8.90, p=.005$, $\eta_{\mathrm{p}}{ }^{2}=.175 ; F_{(1,42)}=8.79, p=.005, \eta_{\mathrm{p}}{ }^{2}=.173$ respectively. Examination of scores showed that not married participants scored higher than married participants on Grace to Others at both Time 2 and Time 3 .

Correlational analyses revealed that age was significantly related to scores on the DSES, EMS, and PANAS$(r=.42, .57$, and -.40 respectively). Age was not significantly related to the DGS, DUREL-I, GQ-6, PANAS+, PosPsych, or SWB. The EMS did not correlate significantly with the DGS for any of the three occasions.

\section{Discussion}

Though the expected changes in marital satisfaction were not found, results indicated that both Congregation $A$ and Congregation $B$ showed an increase in the experience of grace following their respective grace interventions. Congregation A also showed an increase in intrinsic orientation. No changes were found in daily spiritual experiences, gratitude, marital satisfaction, positive or negative affect, attitudes toward positive psychology, or spiritual well-being. Partial eta squared indicated that changes for grace and changes for intrinsic orientation were small. Grace is presumably an ongoing theme in Christian congregations, thus the modest change is not surprising. Similarly, daily spiritual experiences are also likely to be common and were not the focus of the intervention; thus an increase in spiritual experience was an unexpected positive outcome of the grace intervention.

The DGS is relatively new (Bufford et al., 2017); the present results are the first showing that an intervention can increase the self-reported experience of grace, though Patrick et al. (2013) showed a grace intervention could increase empathy, justice, and forgiveness. Contrary to our prediction, not married participants showed greater increases in grace to others than married participants. These results provide support for the utility of the DGS and suggest that it will prove sensitive to differences among groups and changes over time in the experience of grace.

\section{Study Two}

\section{Methods}

\section{Participants}

Again, participants included volunteers from two Friends (Quaker) churches in the Pacific Northwest, though they were not the same congregations used in Study One. These were relatively small congregations with average weekly attendance hovering around 100 parishioners. As with Study One, we attempted to recruit a subset of approximately 30 people per congregation to complete an extensive battery of questionnaires at three time periods. The initial sample included 54 participants, with 27 in each congregation. Of these, 16 were male $(26 \%)$ and 38 female (61\%). The majority (77\%) identified as European American, with 3 (5\%) as Hispanic/Latino, 2 (3\%) as AfricanAmerican, 1 (2\%) as American Indian, and 8 (12\%) not reporting ethnicity. Regarding highest level of education, $4(7 \%)$ reported high school diplomas, 20 (32\%) reported some college courses without a degree, $16(26 \%)$ reported college degrees, and 14 (23\%) reported graduate degrees. The average age of the sample was 52.1 years (standard deviation of 18.8). Using the same crossover design described for Study One, we found attrition over time, with only 31 participants providing data at each of the three assessment periods (13 in Congregation $\mathrm{C}$ and 18 in Congregation D).

\section{Instruments}

The assessment battery used in Study Two involved several scales used in Study One, including the DGS, DSES, DUREL, PPAS, SWB, and demographic questionnaire. Coefficient alphas for Time 1 on these scales were $.86, .95, .76, .84$, and .90 , respectively. In addition, the following scales were unique to this study because of its focus on selfforgiveness in relation to grace.

Heartland Forgiveness Scale (HFS). Trait selfforgiveness was assessed with a part of the Heartland 
Forgiveness Scale (Thompson et al., 2005). The HFS assesses 3 components of forgiveness - self-forgiveness, interpersonal forgiveness, and forgiveness of situations. We utilized only the items related to self-forgiveness, consisting of 6 statements rated on a 7-point Likerttype scale, ranging from 1 (almost always false of me) to 7 (almost always true of me). Thompson et al. (2005) reported alpha reliabilities ranging from .72 to .76 for the self-forgiveness scale of the HFS. In this study we found an alpha of .83 at Time 1.

Differentiated Process Scales of self-forgiveness (DPSSF). To assess state self-forgiveness, participants were prompted to consider an event occurring within the last 6 months, in which they committed an offense against another person. Since much of the research has shown that the severity of the offense is a reliable predictor of self-forgiveness, participants were asked to rate the severity of the offense they outlined in their narrative on a 7-point Likert-type scale, ranging from 1 (not severe at all) to 7 (very severe). State self-forgiveness of that event was then measured utilizing Woodyatt and Wenzel's (2013) Differentiated Process Scales of SelfForgiveness. This scale consists of 19 -items assessing 3 components - self-punitiveness, pseudo self-forgiveness, and genuine self-forgiveness. These statements are rated on a 7-point Likert-type scale, ranging from 1 (do not at all agree) to 7 (strongly agree). Woodyatt and Wenzel (2013) reported internal consistencies of .83 to .89 for self-punitiveness, .69 to .80 for pseudo self-forgiveness, and .46 to .68 for genuine self-forgiveness. At Time 1 we found alpha coefficients of .56 for self-punitiveness, .81 for pseudo self-forgiveness, and .82 for genuine selfforgiveness.

State Self-Forgiveness Scale (SSFS). State selfforgiveness was also assessed using Wohl et al's (2008) State Self-Forgiveness Scale. This consists of 17 statements regarding Self-Forgiving Feelings and Actions (SFFA) and Self-Forgiving Beliefs (SFB). Statements are rated on a 4-point rating scale, ranging from 1 (not at all) to 4 (completely). Wohl et al. (2008) reported alphas of .86 for SFFA and .91 for SFB. At Time 1 we found alphas of .92 for SFFA and .91 for SFB.

God Concept Scales (GCS). Because self-forgiveness is in part related to whether individuals view God as forgiving or punitive, Okun, Johnson, and Cohen's (2013) God Concept Scales were used to measure how participants view God. These consist of 5 statements related to God's benevolence and 5 statements regarding an authoritarian God concept. Statements are rated on a 7-point Likert-type scale, ranging from 1 (strongly disagree) to 7 (strongly agree). Okun et al. (2013) reported alphas of .86 for both the Benevolent God Concept Scale and the Authoritarian God Concept Scale. The reliability for God's benevolence was not strong at Time 1 in the current study ( $\alpha=.38)$, though it was for an authoritarian view of $\operatorname{God}(\alpha=.84)$.

Experiencing God's forgiveness (EGF). In addition, because self-forgiveness has been linked to the experience of God's forgiveness, Martin's (2008) Experiencing God's Forgiveness scale was used. This consists of 5 statements regarding whether participants have experienced forgiveness from God for an offense. Statements are rated on an 11-point Likert-type scale, ranging from 0 (strongly disagree) to 10 (strongly agree). Martin reported an alpha of .75 for the punitive divine forgiveness items and .96 for the positive divine forgiveness items. In the present study at Time 1, reliability was only .29 for the two punitive divine forgiveness items, but was .81 for the three positive forgiveness items.

Responsibility for offense (RFO). Given that acceptance of responsibility is an indicator of genuine self-forgiveness, Fisher and Exline's (2006) Responsibility scale was used to assess the extent to which participants take responsibility for their offense. This scale consists of 5 statements rated on an 11-point Likert-type scale, ranging from 0 (completely disagree) to 10 (completely agree). Fisher and Exline (2006) reported an alpha of .83 for the scale. At Time 1 in the current study alpha reliability was .76 .

\section{Procedure}

The procedures used in Study Two were almost identical to Study One. Again, pastors of the participating churches were invited to collaborate with the researchers in developing the procedures for the grace intervention used in this study. Both congregations developed a'grace emphasis' campaign involving a sermon series, a small-group study program utilizing The Good and Beautiful God by James Bryan Smith (2009), and personal grace practices. In contrast to the 6-week grace intervention used in Study One, this study implemented 9-week interventions in both congregations. As with Study One, participants who completed all three rounds of questionnaires were given a $\$ 50$ gift card. This study was approved by the Human Subjects Research Committee at George Fox University.

\section{Results}

Rather than summing scales, as was done in Study One, average item scores were used to get composite scores for the various scales and subscales. This was done in order to control for missing data that might inadvertently 
Table 3. Study Two means and standard deviations by occasions for all measures.

\begin{tabular}{|c|c|c|c|c|}
\hline Scale & $\begin{array}{c}\text { Congrega- } \\
\text { tion }\end{array}$ & $\begin{array}{c}\text { Time } 1 \mathrm{M} / \\
\mathrm{SD}\end{array}$ & $\begin{array}{c}\text { Time } 2 \mathrm{M} / \\
\mathrm{SD}\end{array}$ & $\begin{array}{c}\text { Time } 3 \mathrm{M} / \\
\text { SD }\end{array}$ \\
\hline \multirow[t]{2}{*}{$\overline{\mathrm{DGS}}$} & A & $4.88 / 0.51$ & $5.12 / 0.71$ & $5.05 / 0.52$ \\
\hline & B & $5.08 / 0.80$ & $5.11 / 0.71$ & $5.43 / 0.72$ \\
\hline \multirow[t]{2}{*}{ DSES } & A & $3.84 / 0.70$ & $4.28 / 0.68$ & $4.21 / 0.95$ \\
\hline & B & $4.72 / 1.01$ & $4.76 / 0.90$ & $5.06 / 0.79$ \\
\hline \multirow[t]{2}{*}{ DUREL-I } & A & $4.18 / 0.75$ & $4.67 / 0.49$ & $4.54 / 0.66$ \\
\hline & B & $4.56 / 0.60$ & $4.46 / 0.72$ & $4.67 / 0.52$ \\
\hline \multirow[t]{2}{*}{ Heartland } & A & $4.97 / 0.78$ & $5.64 / 0.89$ & $5.51 / 1.08$ \\
\hline & B & $4.64 / 1.37$ & $4.73 / 1.25$ & $5.63 / 1.14$ \\
\hline \multirow[t]{2}{*}{ SF Beliefs } & A & $2.18 / 0.31$ & $2.23 / 0.34$ & $2.12 / 0.25$ \\
\hline & B & $2.26 / 0.50$ & $2.20 / 0.25$ & $2.20 / 0.19$ \\
\hline \multirow[t]{2}{*}{ SF Feel \& Act } & A & $2.23 / 0.36$ & $2.24 / 0.36$ & $2.33 / 0.46$ \\
\hline & B & $2.25 / 0.22$ & $2.24 / 0.38$ & $2.33 / 0.34$ \\
\hline \multirow[t]{2}{*}{ Genuine SF } & A & $5.47 / 0.84$ & $5.55 / 1.65$ & $5.61 / 1.13$ \\
\hline & B & $6.46 / 1.65$ & $6.17 / 0.90$ & $6.06 / 1.02$ \\
\hline \multirow[t]{2}{*}{ Pseudo SF } & A & $2.21 / 1.33$ & $2.11 / 1.75$ & $2.09 / 1.36$ \\
\hline & B & $2.23 / 1.32$ & $1.84 / 1.43$ & $1.54 / 0.91$ \\
\hline \multirow[t]{2}{*}{ Punitiveness } & A & $2.73 / 1.24$ & $2.76 / 0.91$ & $3.20 / 0.98$ \\
\hline & B & $2.82 / 1.02$ & $2.69 / 0.97$ & $2.77 / 0.73$ \\
\hline \multirow[t]{2}{*}{ God Forgive } & A & $9.22 / 1.76$ & $9.13 / 2.71$ & $9.36 / 1.67$ \\
\hline & B & $9.64 / 2.06$ & $9.82 / 2.15$ & $10.47 / 1.10$ \\
\hline \multirow[t]{2}{*}{ Responsibility } & A & $8.98 / 1.64$ & $7.82 / 2.90$ & 7.91/1.92 \\
\hline & B & $8.95 / 2.24$ & $8.92 / 2.14$ & $8.11 / 2.56$ \\
\hline \multirow[t]{2}{*}{ Authoritarian } & A & $4.48 / 1.33$ & $4.69 / 1.60$ & $4.99 / 1.10$ \\
\hline & B & $3.67 / 1.77$ & $3.90 / 1.86$ & $3.51 / 1.49$ \\
\hline \multirow[t]{2}{*}{ Benevolent } & A & $6.14 / 0.38$ & $6.32 / 0.37$ & $6.25 / 0.53$ \\
\hline & B & $6.47 / 0.53$ & $6.36 / 0.79$ & $6.49 / 0.55$ \\
\hline \multirow[t]{2}{*}{ Positive Psych } & A & $6.17 / 0.73$ & $6.09 / 0.79$ & $5.88 / 1.07$ \\
\hline & B & $6.26 / 0.84$ & $6.13 / 0.91$ & $6.12 / 1.05$ \\
\hline \multirow[t]{2}{*}{ SWB } & A & $4.41 / 0.43$ & $5.01 / 0.84$ & $4.99 / 0.80$ \\
\hline & B & $4.94 / 0.78$ & $5.20 / 0.81$ & $5.38 / 0.80$ \\
\hline \multirow[t]{2}{*}{ RWB } & A & $4.38 / 0.52$ & $5.14 / 0.74$ & $5.11 / 0.89$ \\
\hline & B & $4.94 / 0.70$ & $5.47 / 0.86$ & $5.55 / 0.72$ \\
\hline \multirow[t]{2}{*}{ EWB } & A & $4.38 / 0.49$ & $4.91 / 0.91$ & $4.88 / 0.76$ \\
\hline & B & $4.80 / 0.91$ & $4.91 / 0.87$ & $5.23 / 0.93$ \\
\hline
\end{tabular}

Notes: $N=31$. DGS = Dimensions of Grace; DSES = Daily Spiritual Experiences; DUREL $=$ Duke Religion Index (1 = question $1 ; 2$ = question $2 ; \mid=$ Intrinsic Religiousness); Heartland $=$ Heartland Forgiveness Inventory; SF Beliefs = Self-forgiving beliefs; SF Feel \& Act = Self-forgiving feelings and actions; Genuine SF = Genuine self-forgiveness; Pseudo SF = Pseudo self-forgiveness; God Forgive = Experiencing God's Forgiveness; Responsibility = Responsibility for Offense; Authoritarian = Authoritarian God Concept; Benevolent = Benevolent God Concept; Positive Psych = Positive Attitude Toward Psychology; SWB = Spiritual Well-Being Scale SWLS = Satisfaction with Life Scale. Scale scores were computed by averaging item responses on each scale and subscale.

distort scale sums (see Table 3 for scores on the outcome measures).

Results were analyzed using mixed measures analyses of variance. On the measure of trait self-forgiveness, the HFS, participants changed over time, $F_{(2,58)}=10.19$, $p<0.001$, and an interaction effect was found, $F_{(2,58)}=4.63$, $p=0.01$, with participants in Congregation $C$ changing between T1 and T2 more than participants in Congregation D. A repeated measures effect was found on the SSFS, with participants reporting greater state self-forgiveness over time for Self-Forgiving Feelings and Actions, $F_{(2,52)}=5.89$, $p=0.005$, as well as Self-Forgiving Beliefs, $F_{(2,52)}=5.79$, $p=0.005$, but the expected interaction effects were not found. No repeated measures or interaction effects were found for the other state self-forgiveness measure or the GCS, EFG, or Responsibility scales. The Genuine
Self-Forgiveness subscale of the DPSSF showed that participants in Congregation D reported higher levels of self-forgiveness than those in Congregation $C, F_{(1,26)}=9.40$, $p=.049$.

Participants changed over time, $F_{(2,58)}=4.07, p=.022$, and an interaction effect was found, $F_{(2,58)}=5.40, p=.007$, on the DUREL. A significant increase in SWB was observed, $F_{(2,58)}=9.94, p<.001$, though no interaction effects were found. This was also true for both the Religious Wellbeing, $F_{(2,58)}=17.16, p<.001$, and Existential Well-being, $F_{(2,58)}=5.64, p=.006$, subscales of the SWB. Similarly the DSES revealed increased spiritual experiences over the course of the study, $F_{(2,58)}=5.34, p=.007$, but no interaction effects. Unlike Study One, changes were not observed on the DGS except that Grace to Self increased over time, $F_{(2,58)}=7.37, p=.001$, with no interaction effects, and a group difference was observed on the Grace to Others scale, with those in Congregation $D$ reporting more grace toward others than those in Congregation $C, F_{(1,29)}=7.53$, $p=.010$, with again, no interaction.

\section{Discussion}

Unlike the findings of Study One, participants in Study Two did not report changes over time regarding their general experience of grace, but both congregations reported increased grace to self and Congregation D reported increased grace to others. Interestingly, grace to self and grace to others correspond nicely with self forgiveness and forgiveness of others. Consistent with our expectations, participants reported increased trait self-forgiveness after participating in the grace intervention; these results are consistent with path analysis findings of Patrick et al. (2013) and extend those of Martin (2008) and McConnell and Dixon (2012). They parallel results of Exline et al. (1999) and Hall and Fincham (2005) as well. Also, one of the two state self-forgiveness measures showed improvement over time for the entire sample, but the changes were not observed during the specific times of the grace interventions in the two congregations. The other state selfforgiveness measure did not show the same effect, but this may be related to us having participants imagine an offense each time they completed the questionnaires with no effort to ensure they were choosing the same offense each time. It could also be due to more rapid changes in state than trait characteristics.

As with Study One, changes in self-reported spiritual experiences were observed over the course of the study. Unlike in Study One, increased spiritual wellbeing was reported by participants in Study Two.

In the case of the DUREL, the expected interaction effect was found, with the grace intervention being associated with greater change than ministry as usual. For other scales 
of religion and spirituality the change occurred over time, but not with the expected interaction effect. This may reflect some spiritual vitality that occurs as a result of participating in a study such as this, regardless of the timing of the grace intervention - or perhaps a Hawthorne effect (McCarney et al., 2007). It also could be due to uncontrolled aspects of grace interventions beginning earlier than planned in Congregation B.

\section{General discussion}

The effects of a grace campaign were examined in two studies completed in Christian church communities. Study One revealed significant increases in scores on the grace measure, providing some support for a hypothesis that self-reported grace can be experimentally increased, echoing Patrick et al. (2013). Whereas Study One found a general increase in grace and in God's grace, Study Two found only a more focal increase in grace to self and, for one congregation, grace to others. Perhaps the use of multiple measures of self-forgiveness over three occasions primed a focus on these aspects of grace for participants in Study Two. In Study One the increase in grace was clearly linked to the intervention, but not in Study Two. These results are somewhat encouraging, as we could locate no prior studies of grace outcomes.

Increased trait self-forgiveness was a general finding of Study Two, with an increase in one measure of state self-forgiveness, but not the others. We found the expected interaction effect with trait self-forgiveness, but not with state self-forgiveness, which would more clearly link increased state self-forgiveness with the grace intervention. Changes in state self-forgiveness could be due to unrelated factors, or may have been a result of Hawthorne effects (McCarney et al., 2007), repeated measurement, or unintended increases in grace or forgiveness emphases in Congregation $B$ during the wait period.

Unexpectedly, both studies showed increases in intrinsic orientation over the study period. These results suggest a possible link between experiencing grace and intrinsic orientation; they also raise the possibility that intrinsic orientation is more amenable to change than we currently think. Much of the study of intrinsic orientation is correlational (Neilsen, Hatton, \& Donahue, 2013); we were unable to locate outcome studies examining this attribute.

Study Two also found increases in spiritual well being both in relationship to God and to present life (self, others, and the world around us). Again, these results are unexpected as spiritual well being is considered a trait rather than a state and tends toward ceiling problems (Bufford, Paloutzian, \& Ellison, 1991; Ledbetter, Smith, Vosler-Hunter, \& Fischer, 1991; Paloutzian \& Ellison, 1982).
Study Two has several implications for self-forgiveness research and practice. First, it suggests that trait selfforgiveness can improve within religious communities who have a strong focus on grace. Second, this is one of the first studies attempting to improve participants' ability to forgive themselves using an intervention, rather than merely describing the characteristics, qualities, or ideas of those who are more able to engage in self-forgiveness. Third, and related to the second, given that many people who seek psychotherapy experience self-loathing, self-condemnation, and have difficulty with forgiving themselves for offenses they have committed against other people, Study Two suggests potential benefits of considering religious and spiritual issues in psychotherapy as clients work through the difficult process of forgiving themselves, an idea suggested by Shafranske (2013). It would be helpful for future research to include clinical samples to examine whether a self-forgiveness intervention that attends to religious and spiritual issues might improve psychological health.

The present studies utilized collaboration between the researchers and four Christian congregations, as proposed by McMinn et al. (2003). These collaborations produced both expected and unexpected consequences. Given that these collaborations occurred within the contexts of four different churches that likely have different needs among their congregants, each congregation had slightly different grace interventions that were tailored to the specific needs of those congregations. All the congregations read the same book in their small group studies, and had access to the weekly grace practices, but the church leaders of each congregation preached different sermons and the book discussions in the study groups focused on the aspects of the book that were deemed relevant for those participants.

This ability to tailor the interventions to the specific needs of different groups is both positive and bothersome. On one hand, it is good to know that significant changes can be experienced, even with, or perhaps because of, these differences in interventions. The effects of the intervention apparently do not require rigidity in implementation and offer strong ecological validity that may make adoption by other congregations more appealing. Additionally, it seems likely that because each congregation was able to somewhat tailor the intervention to their unique needs, collaboration with the churches was better, and there was more enthusiasm for the project than if churches were required to implement an intervention dictated by the psychological researchers involved in the project. However, this fluidity within the research design also poses several challenges. Given the variability introduced by this style of research, it is difficult to determine what aspects of the study contributed to the changes observed here and which had no impact or even detracted 
from the results. Was it the grace practices? The book discussion? Other factors? Also, given the slight differences in the implementation of the grace intervention within each church, it is again difficult to ascertain whether the commonalities or the differences in the implementation had any impact on the results. Future research in more controlled settings might be helpful to clarify what aspects of this study actually contributed to self-forgiveness.

These studies have various limitations. First, the congregations participating in these studies demonstrated significant differences in a variety of important areas even before the beginning of this study. Second, given the differences in the grace interventions among the congregations, it is difficult to determine what promoted change within each church. Third, these results are challenging to generalize to those outside of the Friends community since it is likely that the members of this particular Christian denomination have different views of grace and forgiveness than other Christian denominations and those who are either not Christian or not religious. Fourth, there is potential selection bias because the congregants willing to complete questionnaires were volunteers in both congregations. Finally, participants were mostly white middle-aged adults who were relatively well educated and from Friends (Quaker) congregations; thus generalization to different demographic groups may be limited.

In conclusion, together these findings demonstrated that positive psychology practices can be profitably implemented in local congregations. They also provided support for the utility of the Dimensions of Grace measure, including its subscales, and preliminary support for the hypothesis that the experience of grace can be enhanced through fairly simple methods. Further, they provide preliminary support that a congregation-based grace intervention can promote trait self-forgivingness among parishioners. Somewhat surprisingly, the relatively simple and brief grace campaign also fostered increases in intrinsic religiousness and spiritual well being.

\section{Disclosure statement}

No potential conflict of interest was reported by the authors.

\section{Funding}

This work was supported in part by the John Templeton Foundation [grant number 45112].

\section{References}

Bassett, R. L., \& the Roberts Wesleyan College Psychology Research Group (2013). An empirical consideration of grace and legalism within Christian experience. Journal of Psychology and Christianity, 32, 43-69.
Bufford, R. K., Blackburn, A., Sisemore, T., \& Bassett, R. L. (2015). Finding grace: Preliminary analyses of three measures of grace. Journal of Psychology and Theology, 43, 86-97.

Bufford, R. K., Paloutzian, R. F., \& Ellison, C. W. (1991). Norms for the spiritual well-being scale. Journal of Psychology and Theology, 19, 56-70.

Bufford, R. K., Sisemore, T. A., \& Blackburn, A. M. (April, 2014). Dimensions of grace. Paper presented at the 2014 annual meeting of the Christian Association for Psychological Studies, Atlanta, GA.

Bufford, R. K., Sisemore, T. A., \& Blackburn, A. M. (2017). Dimensions of grace: Factor analysis of three grace scales. Psychology of Religion and Spirituality., 9, 56-69.

Crawford, J. R., \& Henry, J. D. (2004). The positive and negative affect schedule (PANAS): Construct validity, measurement properties and normative data in a large non-clinical sample. British Journal of Clinical Psychology, 43, 245-265.

Crowne, D. P., \& Marlowe, D. (1960). A new scale of social desirability independent of psychopathology. Journal of Consulting Psychology, 24, 349-354.

Ellison, C. W. (1983). Spiritual well-being: Conceptualization and measurement. Journal of Psychology and Theology, 11, 330-340.

Enders, C. K. (2010). Applied missing data analysis. New York, NY: Guilford Press.

Exline, J. J., Yali, A. M., \& Lobel, M. (1999). When God disappoints: Forgiving Godandits roleinnegativeemotion.JournalofHealth Psychology, 4, 365-379. doi:10.1177/135910539900400306

Fisher, M. L., \& Exline, J. J. (2006). Self-forgiveness versus excusing: The roles of remorse, effort, and acceptance of responsibility. Self and Identity, 5, 127-146. doi:10.1080/ 15298860600586123

Fowers, B. J., \& Olson, D. H. (1993). ENRICH Marital Satisfaction Scale: A brief research and clinical tool. Journal of Family Psychology, 7, 176-185. doi:10.1037/0893-3200.7.2.176

Hall, J. H., \& Fincham, F. D. (2005). Self-forgiveness: The stepchild of forgiveness research. Journal of Social and Clinical Psychology, 24, 621-637. doi:10.1521/jscp.2005.24.5.621

Koenig, H. G., \& Bussing, A. (2010). The Duke University Religion Index (DUREL): A five-item measure for use in epidemiological studies. Religions, 1, 78-85. doi:10.3390/rel1010078

Koenig, H. G., Meador, K. G., \& Parkerson, G. (1997). Religion index for psychiatric research. American Journal of Psychiatry., 154, 885-886.

Leach, M. M., \& Lark, R. (2004). Does spirituality add to personality in the study of trait forgiveness? Personality and Individual Differences, 37, 147-156. doi:10.1016/j.paid.2003.08.007

Ledbetter, M. F., Smith, L. A., Vosler-Hunter, W. L., \& Fischer, J. D. (1991). An evaluation of the research and clinical usefulness of the spiritual well-being scale. Journal of Psychology and Theology, 19, 49-55.

Martin, A. M. (2008). Exploring forgiveness: The relationship between feeling forgiven by God and self-forgiveness for an interpersonal offense. Dissertation Abstracts International: Section B. Sciences and Engineering, 69, 3900.

McCarney, R., Warner, J., lliffe, S., van Haselen, R., Griffin, M., \& Fisher, P. (2007). The Hawthorne Effect: A randomised, controlled trial. BMC Medical Research Methodology, 7, 53. doi:10.1186/1471-2288-7-30. PMC 1936999. PMID 17608932

McConnell, J. M., \& Dixon, D. N. (2012). Perceived forgiveness from God and self-forgiveness. Journal of Psychology and Christianity, 31, 31-39. 
McCullough, M. M., Emmons, R. A., \& Tsang, J. (2002). The grateful disposition: A conceptual and empirical topography. Journal of Personality and Social Psychology, 82, 112-127. doi:10.1037/0022-3514.82.1.112

McLaughlin, P. T., McMinn, M. R., Morse, M., Neff, M. A., Johnson, B., Summerer, A., \& Koskela, N. (in press). The effects of a wisdom intervention in a Christian congregation. Journal of Positive Psychology., 82, 112-127.

McMinn, M. (2008). Sin and grace in Christian counseling. Downers Grove, IL: Intervarsity Press.

McMinn, M. R., Aikins, D. C., \& Lish, R. (2003). Basic and advanced competence in collaborating with clergy. Professional Psychology: Research and Practice, 34, 197-202. doi:10.1037/0735-7028.34.2.197

Moody, J. A. (2016). The effects of a grace intervention on a Christian congregation: A study of positive psychology in the church (Unpublished doctoral dissertation). George Fox University, Newberg, OR.

Neilsen, M. E., Hatton, A.T., \& Donahue, M. J. (2013). Religiousness, social psychology, and behavior. In R. F. Paloutzian, \& C. L. Park (Eds.), Handbook of the psychology of religion and spirituality (pp. 312-329). New York, NY: Guilford.

Okun, M. A., Johnson, K. A., \& Cohen, A. B. (2013). Beliefs about God, closeness to God, and intent to volunteer. Poster session presented at Annual Convention of the American Psychological Association, Honolulu, Hawaii.

Paloutzian, R. F., \& Ellison, C. W. (1982). Loneliness, spiritual well-being and quality of life. In L. A. Peplau, \& D. Perlman (Eds.), Loneliness: A sourcebook of current theory, research and therapy (pp. 224-236). New York, NY: Wiley.

Patrick, S., Beckenbach, J., Sells, J., \& Reardon, R. F. (2013). An empirical investigation into justice, grace, and forgiveness: Paths to relationship satisfaction. The Family Journal: Counseling and Therapy for Couples and Families, 21, 142-153. doi:10.1177/1066480712466540

Pigott, T. D. (2001). A review of methods for missing data. Educational Research and Evaluation, 7, 353-383.

Reynolds, W. M. (1982). Development of reliable and valid short forms of the marlowe-crowne social desirability scale. Journal of Clinical Psychology, 38, 119-125.

Seligman, M. E. P., \& Csikszentmihalyi, M. (2000). Positive psychology: An introduction. American Psychologist., 55, 5-14. doi:10.1037//0003-066X.55.1.5

Seligman, M. E. P., Steen, T. A., Park, N., \& Peterson, C. (2005). Positive psychology progress: Empirical validation of interventions. American Psychologist, 60, 410-421. doi:10.1037/0003-066X.60.5.410

Shafranske, E. P. (2013). Addressing religiousness and spirituality in psychotherapy. In R. F. Paloutzian, \& C. L. Park (Eds.), Handbook of the psychology of religion and spirituality (pp. 595-616). New York, NY: Guilford.

Sisemore, T. A., Swanson, M., Arbuckle, M., Fisher, R., Lillian, M., McGinnis, J., \& Mortellaro, E. (2011). Grace and Christian psychology - Part 1: Preliminary measurement, relationships, and implications for practice. Edification: The Transdisciplinary Journal of Christian Psychology, 4, 57-63.

Smith, J. B. (2009). The good and beautiful God: Falling in love with the God Jesus knows. Downers Grove, IL: Intervarsity Press.
Storch, E. A., Roberti, J. W., Heidgerken, A. D., Storch, J. B., Lewin A. B., Killiany, E. M., ... Geffken, G. R. (2004). The Duke religion index: A psychometric investigation. Pastoral Psychology, $53,7$.

Thompson, L. Y., Snyder, C. R., Hoffman, L., Michael, S. T., Rasmussen, H., Billings, L. S, ... Roberts, D.E. (2005). Dispositional forgiveness of self, others, and situations. Journal of Personality, 73, 313-360. doi:10.1111/j.14676494.2005.00311.x

Toussaint, L., \& Williams, D. R. (2008). National survey results for Protestant, Catholic, and nonreligious experiences of seeking forgiveness and of forgiveness of self, of others, and by God. Journal of Psychology and Christianity, 27, 120-130.

Uhder, J., McMinn, M. R., Bufford, R. K., \& Gathercoal, K. (2017). A gratitude intervention in a Christian church community. Journal of Psychology and Theology, 45, 46-57.

Underwood, L. G. (2011). The daily spiritual experience scale: Overview and results. Religions, 2, 29-50. doi:10.3390/ rel2010029

Underwood, L. G., \& Teresi, J. A. (2002). The daily spiritual experience scale: Development, theoretical description, reliability, exploratory factor analysis, and preliminary construct validity using health-related data. Annals of Behavioral Medicine, 24, 22-33.

Walker, D. F., \& Gorsuch, R. L. (2002). Forgiveness within the Big Five personality model. Personality and Individual Differences, 32, 1127-1137. doi:10.1016/S0191-8869(00)00185-9

Watson, P. J., Chen, Z., \& Sisemore, T. A. (2011). Grace and Christian psychology - Part 2: Psychometric refinements and relationships with self-compassion, depression, beliefs about sin, and religious orientation. Edification: The Transdisciplinary Journal of Christian Psychology, 4, 64-72.

Watson, D., Clark, L. A., \& Tellegen, A. (1988). Development and validation of brief measures of positive and negative affect: The PANAS scales. Journal of Personality and Social Psychology, 54, 1063-1070. doi:10.1037/0022-3514.54.6.1063

Watson, P. J., Morris, R. J., \& Hood, R. W., Jr (1988a). Sin and selffunctioning, Part 1: Grace, guilt, and self-consciousness. Journal of Psychology and Theology, 16, 254-269.

Watson, P. J., Morris, R. J., \& Hood, R. W., Jr (1988b). Sin and self-functioning, Part 2: Grace, guilt, and psychological adjustment. Journal of Psychology and Theology, 16, 270-281.

Wenzel, M., Woodyatt, L., \& Hedrick, K. (2012). No genuine self-forgiveness without accepting responsibility: Value reaffirmation as a key to maintaining positive self-regard. European Journal of Social Psychology, 42, 617-627. doi:10/1002/ejsp.1873

Wohl, M. J. A., DeShea, L., \& Wahkinney, R. L. (2008). Looking within: Measuring state self-forgiveness and its relationship to psychological well-being. Canadian Journal of Behavioural Science, 40, 1-10. doi:10.1037/0008-400x.40.1.1.1

Wood, A. M., Joseph, S., \& Maltby, J. (2009). Gratitude predicts psychological well-being above the Big Five facets. Personality and Individual Differences, 46, 443-447.

Woodyatt, L., \& Wenzel, M. (2013). Self-forgiveness and restoration of an offender following an interpersonal transgression. Journal of Social and Clinical Psychology, 32, 225-259. doi:10.1521/jscp.2013.32.2.225 